\title{
O USO DO GENOGRAMA E ECOMAPA COMO ESTRATÉGIA DE COLETA DE DADOS EM PESQUISAS COM FAMÍLIAS
}

\author{
Erika Sana Moraes \\ Enfermeira da UTI Pediátrica do Hospital de Clínicas da Unicamp, \\ Doutoranda da Faculdade de Enfermagem da Unicamp. \\ kehmoraes@gmail.com
}

INTRODUÇÃO: Atualmente, tem crescido no Brasil o número de pesquisas de abordagem qualitativa destinadas à compreensão de fenômenos de saúde e doença sob uma perspectiva do sistema familiar, e não de seus membros isoladamente. Neste contexto, é indispensável a seleção cuidadosa de instrumentos de avaliação familiar que possam trazer dados significativos a partir de uma visão sistêmica. O Modelo Calgary de Avaliação Familiar apresenta dois instrumentos consagrados na prática clínica para avaliar famílias, a saber, o genograma e o ecomapa. Estudos recentes tem mostrado que o seu uso para fins de pesquisa é crescente e promissor. OBJETIVO: discutir a aplicabilidade do genograma e ecomapa como estratégia de coleta de dados em pesquisas com famílias. MÉTODO: Relato de experiência, em que as autoras apresentam os instrumentos e descrevem uma proposta de utilização dos mesmos como estratégia de coleta de dados, bem como os desafios inerentes à análise e triangulação destes achados com as demais fontes de coleta de dados. RESULTADOS: O genograma tem por objetivo estabelecer um retrato da composição familiar, e seu uso em pesquisas também promovem o quebra-gelo antes do início das entrevistas, além de fornecer dados importantes sobre a composição interna da família. O ecomapa, destinado a identificar como a família se relaciona com a comunidade, é imprescindível quando se busca conhecer e compreender experiências de apoio social ou privação de suporte nos desafios de saúde. Interpretá-los em conjunto com os demais dados coletados enriquece a compreensão das experiências familiares, à medida que a estrutura familiar é compreendida e fundamenta os demais achados. CONSIDERAÇÕES FINAIS: O genograma e ecomapa mostram-se úteis às pesquisas com famílias, e o uso destes instrumentos deve ser encorajado.

Palavras-chave: Genograma. Ecomapa. Coleta de dados. Sistema familiar. 